\title{
Hydrate morphology: Physical properties of sands with patchy hydrate saturation
}

\author{
S. Dai, ${ }^{1}$ J. C. Santamarina, ${ }^{1}$ W. F. Waite, ${ }^{2}$ and T. J. Kneafsey ${ }^{3}$ \\ Received 30 July 2012; revised 18 September 2012; accepted 29 September 2012; published 14 November 2012.
}

[1] The physical properties of gas hydrate-bearing sediments depend on the volume fraction and spatial distribution of the hydrate phase. The host sediment grain size and the state of effective stress determine the hydrate morphology in sediments; this information can be used to significantly constrain estimates of the physical properties of hydrate-bearing sediments, including the coarse-grained sands subjected to high effective stress that are of interest as potential energy resources. Reported data and physical analyses suggest hydrate-bearing sands contain a heterogeneous, patchy hydrate distribution, whereby zones with $100 \%$ pore-space hydrate saturation are embedded in hydrate-free sand. Accounting for patchy rather than homogeneous hydrate distribution yields more tightly constrained estimates of physical properties in hydrate-bearing sands and captures observed physical-property dependencies on hydrate saturation. For example, numerical modeling results of sands with patchy saturation agree with experimental observation, showing a transition in stiffness starting near the series bound at low hydrate saturations but moving toward the parallel bound at high hydrate saturations. The hydrate-patch size itself impacts the physical properties of hydrate-bearing sediments; for example, at constant hydrate saturation, we find that conductivity (electrical, hydraulic and thermal) increases as the number of hydrate-saturated patches increases. This increase reflects the larger number of conductive flow paths that exist in specimens with many small hydrate-saturated patches in comparison to specimens in which a few large hydrate saturated patches can block flow over a significant cross-section of the specimen.

Citation: Dai, S., J. C. Santamarina, W. F. Waite, and T. J. Kneafsey (2012), Hydrate morphology: Physical properties of sands with patchy hydrate saturation, J. Geophys. Res., 117, B11205, doi:10.1029/2012JB009667.

\section{Introduction}

[2] Engineering protocols and stability analyses needed for safe gas production from hydrate-bearing sediments require accurate information about the sediment's physical properties and their dependence on hydrate volume fraction and spatial distribution. Prior to the early 1980s, methane gas hydrate was assumed to be uniformly distributed wherever pressure and temperature conditions were appropriate [Milkov, 2004; Trofimuk et al., 1973]. Subsequent studies have revealed a heterogeneous global distribution, due in part to the importance of advective transport in supplying sufficient methane for hydrate formation [McIver, 1981; Gornitz and Fung, 1994; Buffett and Archer, 2004; Wood and Jung, 2008], as well as

\footnotetext{
${ }^{1}$ School of Civil and Environmental Engineering, Georgia Institute of Technology, Atlanta, Georgia, USA.

${ }^{2}$ U.S. Geological Survey, Woods Hole, Massachusetts, USA.

${ }^{3}$ Lawrence Berkeley National Laboratory, Berkeley, California, USA.

Corresponding author: S. Dai, School of Civil and Environmental Engineering, Georgia Institute of Technology, 790 Atlantic Dr., Atlanta, GA 30332-0355, USA. (sheng.dai@gatech.edu)

(C)2012. American Geophysical Union. All Rights Reserved. 0148-0227/12/2012JB009667
}

spatially varying sediment properties such as grain size and porosity [Clennell et al., 1999; Waite et al., 2009].

[3] Connections between the sediment type, burial conditions, and resulting hydrate distributions are becoming more apparent as the inventory of high-resolution images of recovered hydrate-bearing cores increases. We have taken advantage of X-ray computed tomography [Holland et al., 2008; Kneafsey et al., 2010], micro-CT [Jin et al., 2006; Kerkar et al., 2009], and magnetic resonance [Kleinberg et al., 2003; Stevens et al., 2008; Ersland et al., 2010] to explore hydrate occurrence patterns in all types of nature al sediments, and present a first-order physical model to analyze these patterns in terms of environmental conditions and sediment characteristics. Focusing on high value, energy resource environments, we then estimate a suite of physical properties for hydrate-bearing sands, containing patches of $100 \%$ hydratesaturated sand embedded in water-filled sand.

\section{Hydrate in Porous Media: Patterns}

\subsection{Nucleation and Growth}

[4] Hydrate nucleation is favored at the water-gas interface when free gas is present [Tohidi et al., 2001; Kleinberg 
et al., 2003; Waite et al., 2004], and on mineral surfaces in the absence of free gas due to the reduced thermal activity and spatial distribution of water molecules in the vicinity of mineral surfaces [Dominguez et al., 2000; Page and Sear, 2006]. Under stable pressure and temperature conditions, molecules continuously jump from one phase to the other in hydrate-water or hydrate-gas systems, and a minimum crystal size $d_{c r}$ of several nanometers must be reached to ensure a stable nucleus for gas-hydrate growth [Lee, 2007]. Eventually, stable nuclei grow into the pore space between sediment grains. Continued molecular transfer across phases can gradually change the spatial hydrate distribution in sediments, concentrating hydrate into fewer, larger crystals [Myerson, 2002]. This "Ostwald-ripening" phenomenon occurs because the methane concentration is higher around smaller hydrate crystals according to the Gibbs-Thompson effect [Henry et al., 1999; Kwon et al., 2008], and diffusive transport develops from the higher methane concentrations surrounding smaller crystals toward larger crystals.

[5] Eventually, hydrate growth becomes constrained by the mineral grains. Further growth takes place by either invading neighboring pores or displacing particles to enlarge the occupied pores. Whether growth occurs in a grain-displacing or pore-filling manner depends on the balance between the local effective stress and the capillary pressure developed by the hydrate mass. At equilibrium, the pressure in the hydrate phase $u_{h}$ must balance the pressure in the water phase $u_{w}$ and the effective stress acting on the grain skeleton $\sigma^{\prime}$ for a large interface:

$$
u_{h}=u_{w}+\sigma^{\prime}
$$

In addition, pressures in the hydrate $u_{h}$ and water $u_{w}$ phases are related through Laplace's equation [Clennell et al., 1999; Coussy, 2010]

$$
\left(u_{h}-u_{w}\right)=\frac{4 \gamma_{h w} \cos \theta}{d_{t h}},
$$

where the contact angle is assumed here to be $\theta=0^{\circ}$, and the hydrate-water interfacial tension is $\gamma_{h w}=0.032-0.039 \mathrm{~N} / \mathrm{m}$ [Uchida et al., 1999; Anderson et al., 2003]. The pore throat diameter $d_{t h}$ is determined by the fine sediment fraction, taken here to be the finest 10th percentile in the grain size distribution. The pore throat diameter is $d_{t h} \cong(\sqrt{2}-1) d_{10}$ for simple cubic packing. These equations are combined to define a dimensionless parameter:

$$
\psi=\frac{\left(\frac{4 \gamma_{h w}}{d_{t h}}\right)}{\sigma^{\prime}}=\frac{4 \gamma_{h w}}{(\sqrt{2}-1) d_{10} \sigma^{\prime}} \cong \frac{10 \gamma_{h w}}{d_{10} \sigma^{\prime}},
$$

which reflects the relative balance between hydrate-water capillarity and effective stress. When $\psi>1$, capillarity prevails and hydrate can displace particles more readily than invade pore throats; thus, we anticipate that fine-grained soils (small $d_{10}$ ) under low effective stress $\sigma^{\prime}$ are prone to graindisplacement and segregated hydrate formation. Conversely, $\psi<1$ corresponds to coarse-grained sediments (large $d_{10}$ ) subjected to high effective stress $\sigma^{\prime}$, and hydrate growth will fill and invade existing pores rather than displace grains. Therefore, Ostwald ripening in coarse-grained sediments will promote patchy hydrate distributions, whereby hydrate-filled sediment patches $\left(S_{h}=100 \%\right)$ are embedded in a hydrate-free sediment $\left(S_{h}=0 \%\right)$.

\subsection{Hydrate Occurrence Patterns: Field Evidence}

[6] Reported hydrate morphologies in natural hydratebearing sediments are summarized in Table 1, together with reservoir location, core depth, and sediment characteristics. Figure 1 shows the same data plotted in terms of vertical effective stress $\sigma_{v}^{\prime}$ versus effective grain size $d_{10}$. The vertical effective stress is calculated using the sediment depth and an assumed sediment density of $2000 \mathrm{~kg} / \mathrm{m}^{3}$. The effective grain size $d_{10}$ is estimated from reported grain size distributions and sediment descriptions.

[7] Observations show that naturally occurring hydrate exhibits three general morphologies: pore-fill, lenses/veins, and nodules/chunks [Collett et al., 2009; Holland et al., 2008]. As shown in Figure 1, pore-filling hydrate morphology corresponds to deep, coarse-grained sediments for which $\psi<10^{-3}$. Hydrate forms in nodules and chunks when hydrate crystals can grow by displacing particles in every direction in an entirely hydrate-water capillarity dominated regime where $\psi>1$. At intermediate conditions, $10^{-3}<\psi<1$, hydrate growth is capillarity controlled but grain displacement is preferentially aligned normal to the local minimum principal stress $\sigma_{3}^{\prime}$ and leads to lens formation [Shin and Santamarina, 2011; Cook et al., 2008; Daigle and Dugan, 2010].

\section{Physical Property Estimation for Patchy Saturation: Methods}

[8] The physical properties of hydrate-bearing sediments depend on the spatial distribution of gas hydrate, which is generally not known a priori. Observations summarized in Figure 1 allow us to constrain the range of possible morphologies, and thereby tighten realistic upper and lower bounds for physical property values.

[9] In particular, pore-filling conditions $\left(\psi<10^{-3}\right)$ and Ostwald ripening combine to generate "patchy hydrate saturation" in mature hydrate-bearing coarse-grained sediments. From a modeling perspective, patchy saturation is a twocomponent combination of hydrate-saturated sand patches $\left(S_{h}=100 \%\right)$ embedded in water-saturated, hydrate-free sediment $\left(S_{h}=0 \%\right)$, rather than a three-component system (either mineral-hydrate-water or mineral-hydrate-gas). In the following sections, we use analytical models and numerical simulations to estimate core-scale physical properties of patchy hydrate-bearing sediments, and demonstrate the benefits of utilizing the two-component nature of the patchy hydrate distribution to provide a tighter range of physical property estimates than can be obtained for a three-component system. Note that logging and seismic investigations operate at lower resolution [Shankar and Riedel, 2011] and are less sensitive to hydrate morphology [Knight and Nolenhoeksema, 1990; Li et al., 2001]; instead, they reflect larger lithologicscale heterogeneities (reviewed in Waite et al. [2009]).

\subsection{Upper and Lower Bounds}

[10] Upper and lower bounds can be computed for a given physical property by assuming end-member arrangements of the components (Tables $2 \mathrm{a}$ and $2 \mathrm{~b}$ ). The parallel and series configurations, also known as the Voigt and Reuss models, are easily calculated but are broader than necessary. Tighter 


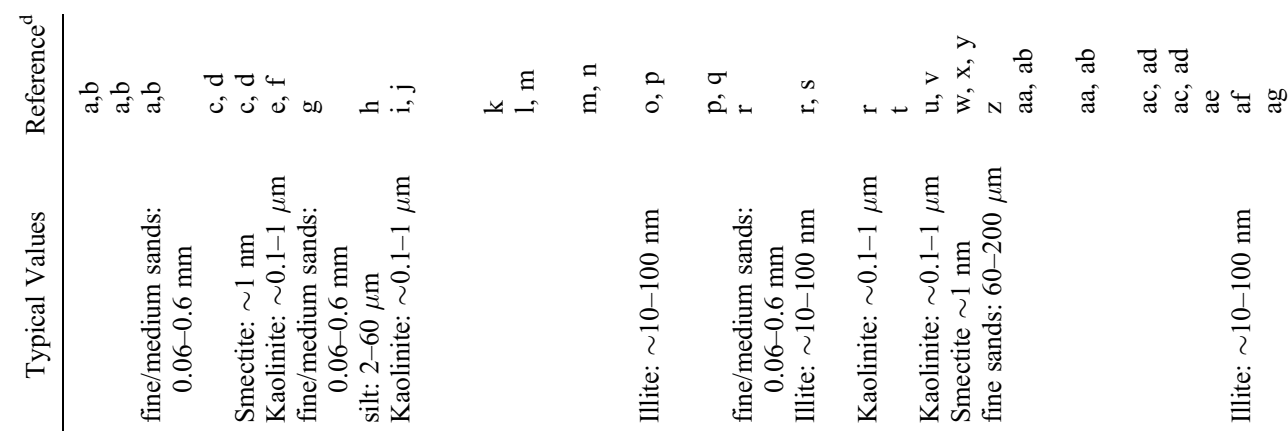

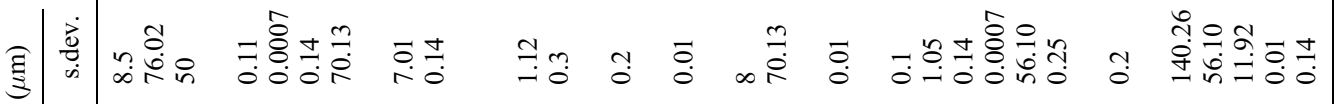
苛

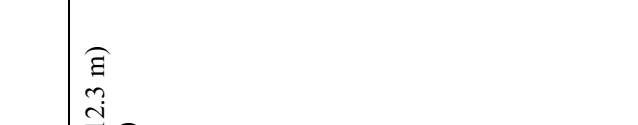<smiles>C1CCC(C2CCCC2)C1</smiles>

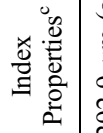
$\stackrel{8}{\circ}$ 要 空

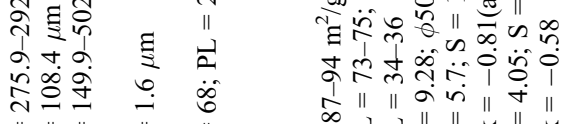
"I"

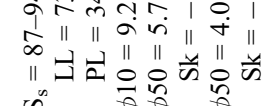
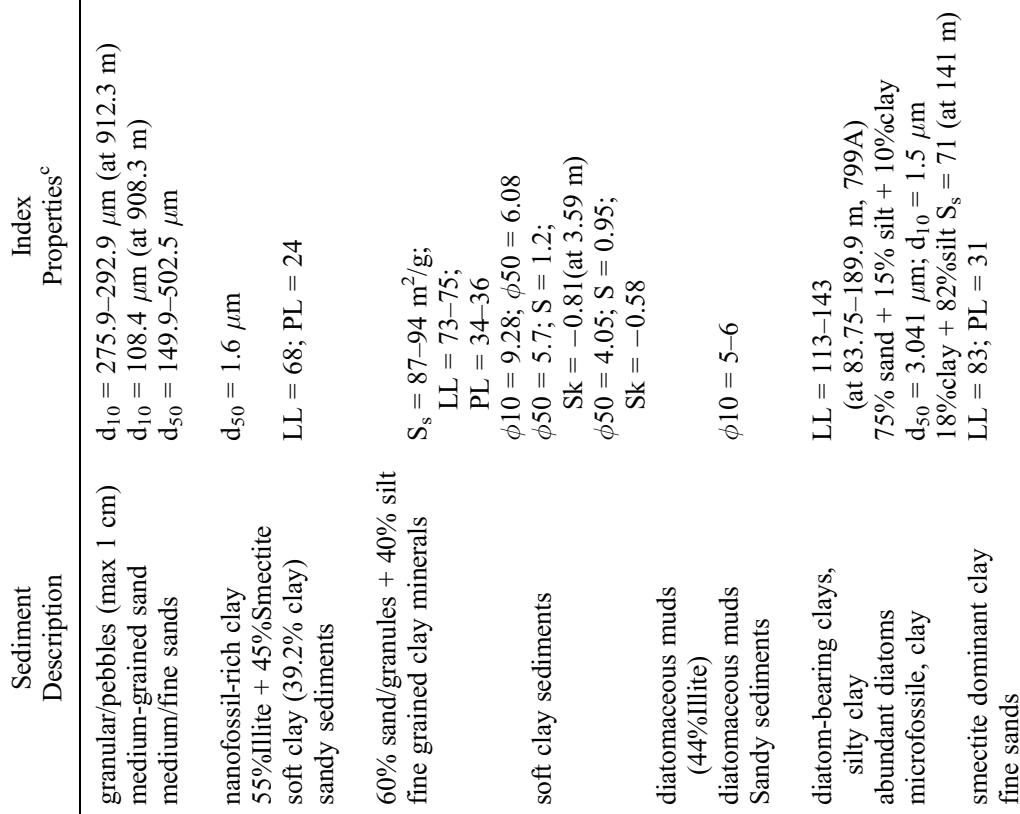
$\stackrel{\square}{\bar{m}}$

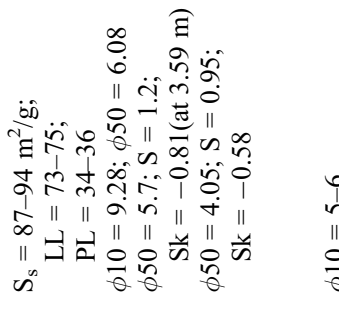

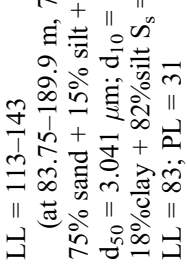

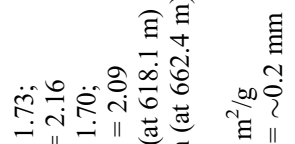

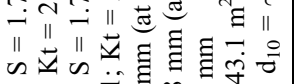

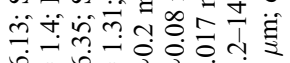

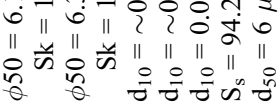

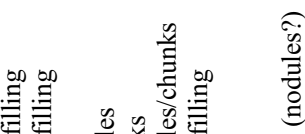

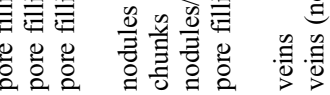

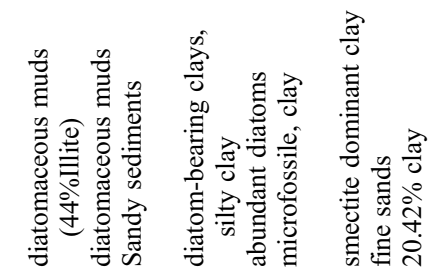

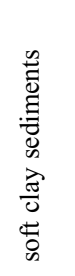
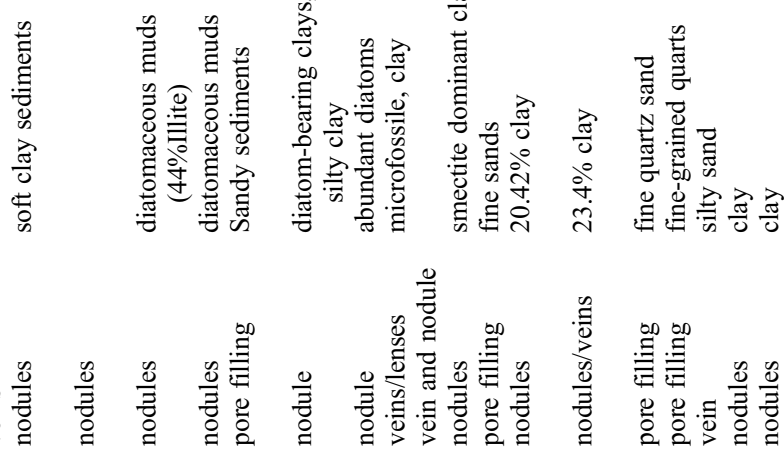

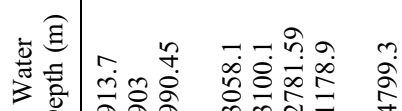

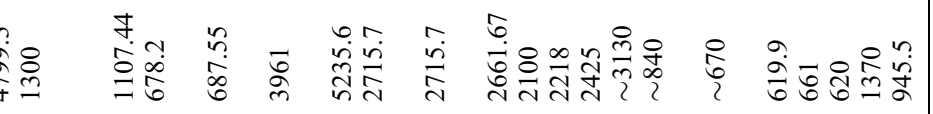

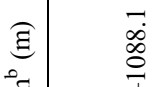

䓂 तु

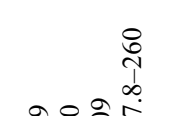

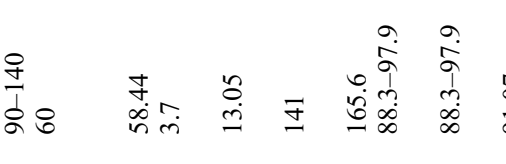
तेलिलंते श्ष

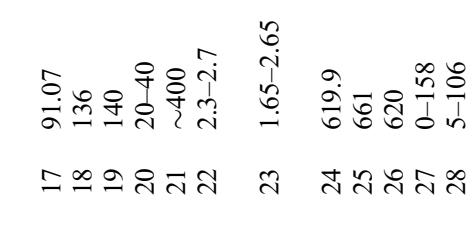
$\therefore=\simeq \stackrel{ \pm}{\simeq}$
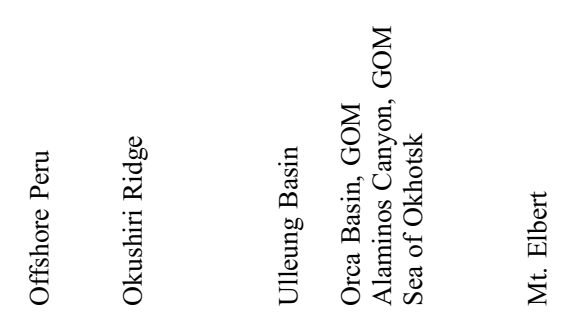

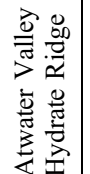

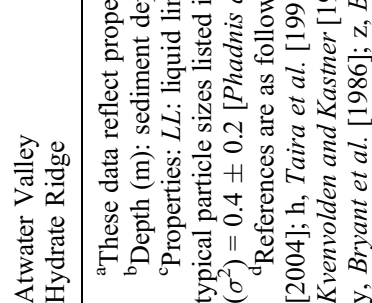




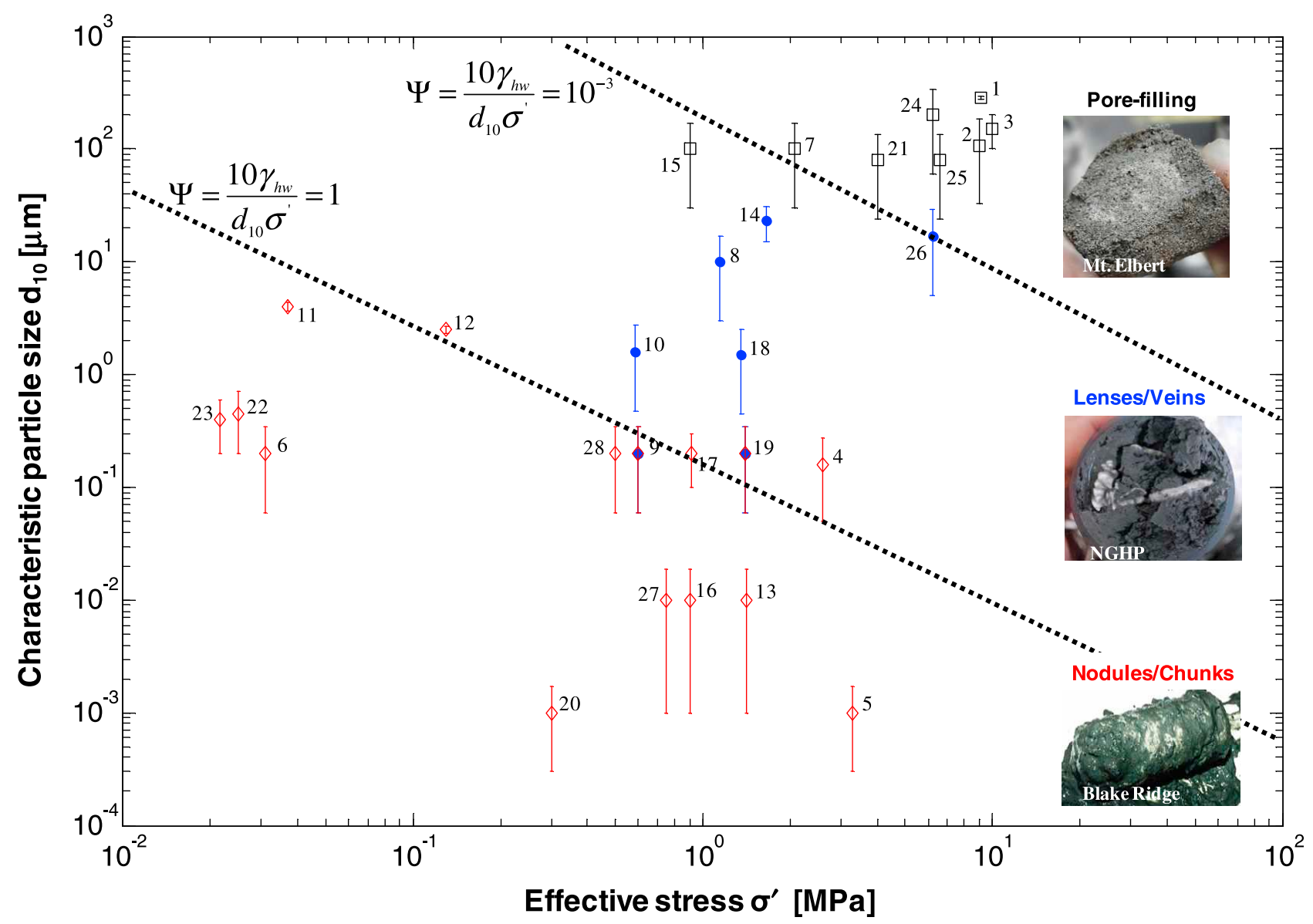

Figure 1. Hydrate morphologies in natural sediments - Field evidence and $\psi$-boundaries. In response to a combination of sediment particle size and effective stress, hydrate formation occurs in one of three general morphologies: Environments with relatively large sediment grains and high effective stress can host pore-filling hydrates (top inset); in contrast, hydrates forming in fine-grained sediment with low effective stress can displace sediment grains in all directions and create hydrate nodules or chunks (bottom inset). Between these two extremes, hydrate formation responds to variations in the local stress, displacing sediment grains in the directions of the smallest stress to form hydrate lenses and veins (middle inset). All data are based on core analysis and do not necessarily reflect reservoir properties (refer to Table 1 for details).

bounds are computed assuming the shell-like arrangement of individual components described by Hashin and Shtrikman [1962, 1963], and illustrated in Tables 2a and 2b. HashinShtrikman bounds apply to hydraulic, thermal, and electrical conductivities, electrical permittivity, magnetic permeability, and both bulk and shear moduli.

\subsection{Analytical Models}

[11] Effective medium models can be used to estimate physical properties of mixtures when their spatial configuration is known (Tables $3 a$ and $3 b$ ). The Kuster-Toksöz effective medium model estimates effective properties of a combined medium with known host and patch properties, and it can account for patch shape, e.g., spherical, needle-like, and diskshaped cracks [Kuster and Toksöz, 1974; Berryman, 1995]. The model converges to the Hashin-Shtrikman upper or lower bounds for spherical patches. Due to the asymmetric nature of this model, results depend on the material selected to be either the patch or the host. In contrast, the self-consistent model is symmetric, meaning all components in the system are considered to be patchy inclusions, and the numerical results are the same regardless of which material is defined as the patch, and which is defined as the host [Berryman, 1980]. The bulk and shear moduli must be iteratively solved in this model, but other properties are computed directly, including conductivity, permeability, and permittivity (see Tables $3 a$ and $3 b$ ). These analytical models address first order quasi-static effects,

Table 2a. Physical Properties and Upper and Lower Bound Models: General Expressions ${ }^{\mathrm{a}}$

\begin{tabular}{lllc}
\hline \multicolumn{1}{c}{ Model } & Bound & \multicolumn{1}{c}{ Equation } & Equation Number \\
\hline Voigt (parallel) $^{\mathrm{b}}$ & Upper & $X=\sum f_{i} x_{i}$ & T1 \\
Reuss (series) $^{\mathrm{b}}$ & Lower & $X=\left(\sum f_{i} / x_{i}\right)^{-1}$ & $\mathrm{~T} 2$ \\
Hashin-Shtrikman $^{\mathrm{c}}$ & Upper & $X=x_{\max }+\frac{\xi A_{\max }}{1-\xi_{A_{\max }} A_{\max }}$ & $\mathrm{T} 3$ \\
& Lower & $X=x_{\min }+\frac{\alpha_{\min } A_{\min }}{1-\alpha_{\min }}$ & $\mathrm{T} 4$ \\
\hline
\end{tabular}

${ }^{\mathrm{a}} X$ - bulk property of the mixture; $x_{i}$ - physical property of the $i$ th constituent; $f_{i}$ - volume fraction of the $i$ th constituent; $A_{\max , \min }=$ $\sum \frac{f_{i}}{\alpha_{\max , \min }+\xi /\left(x_{i}-x_{\max , \min }\right)}$, see Table $2 \mathrm{~b}$ for $\alpha$ and $\xi$.
${ }^{\mathrm{b}}$ Mavko et al. $[1998]$.
${ }^{\mathrm{c}}$ Hashin and Shtrikman [1962, 1963]. 
Table 2b. Property-Dependent $\alpha$ and $\xi$ Parameters, to Be Substituted Into the Expressions for $X$ and $A_{\max , \min }$ From Table $2 \mathrm{a}^{\mathrm{a}}$

\begin{tabular}{|c|c|c|c|}
\hline \multirow[b]{2}{*}{ Properties } & \multicolumn{2}{|c|}{$\alpha$} & \multirow[b]{2}{*}{$\xi$} \\
\hline & $\max$ & $\min$ & \\
\hline $\begin{array}{l}\text { Hydraulic conductivity } k_{H}{ }^{\text {b,c }} \\
\text { Thermal conductivity } \lambda^{\mathrm{d}} \\
\text { Electrical conductivity } \sigma_{e}{ }^{\mathrm{d}} \\
\text { Magnetic permeability } \mu^{\mathrm{d}} \\
\text { Dielectric permittivity } \varepsilon_{r}^{\mathrm{d}} \\
\text { Bulk modulus } K^{\mathrm{e}}\end{array}$ & $\alpha_{\max }=\frac{3}{3 K_{\max }+4 G_{\max }}$ & $\alpha_{\min }=\frac{3}{3 K_{\min }+4 G_{\min }}$ & $\xi=1$ \\
\hline Shear modulus $G^{\mathrm{e}}$ & $\alpha_{\max }=\frac{3\left(K_{\max }+2 G_{\max }\right)}{5 G_{\max }\left(3 K_{\max }+4 G_{\max }\right)}$ & $\alpha_{\min }=\frac{3\left(K_{\min }+2 G_{\min }\right)}{5 G_{\min }\left(3 K_{\min }+4 G_{\min }\right)}$ & $\xi=0.5$ \\
\hline
\end{tabular}

and are well-suited for providing a unified approach for estimating a suite of physical properties even in cases where only basic field data are available.

[12] More specialized physical property treatments of patchy-saturated rocks [e.g., Dvorkin and Nur, 1998; Vogelaar et al., 2010; Quintal et al., 2011; see also Mavko and Mukerji, 1998] generally deal with gas patches embedded within fluidsaturated media, where both gas-filled and fluid-fill patches have identical shear stiffness (or shear wave velocity). This uniform shear stiffness simplification cannot be applied to hydrate-filled patches where solid hydrate significantly enhances the stiffness of hydrate-filled sediment. Our lowfrequency models do not consider dispersion due to either viscous losses or polarization effects [Asami, 2005].

\subsection{Numerical Simulations}

[13] Numerical simulations allow us to capture conditions beyond the assumptions made in analytical models. In this study, simulations were implemented in COMSOL Multiphysics. We use cylindrical specimens (radius $R=0.05 \mathrm{~m}$ and height $H=0.2 \mathrm{~m}$ ) containing spherical hydrate-saturated sand patches. The number of patches varies from 1 to 200 while the specimen's hydrate saturation is held constant $\left(S_{h}=0.2\right)$. Several realizations of randomly distributed patches are generated for a given number of hydrate patches. The properties of hydrate-saturated sand patches and hydrate-free sand matrix listed in Table 4 are used as inputs to the numerical model.

[14] The 3D numerical model is meshed using tetrahedral element, and the number of elements increases with the number of patches, varying from $\sim 10,000$ to $\sim 300,000$. To compute moduli, the cylindrical specimen is loaded with an isotropic stress $\sigma_{i}$ and the bulk modulus $K$ is calculated as
$K=\Delta \sigma_{i} / \Delta \varepsilon_{v}$, where $\Delta \varepsilon_{v}$ is the computed volumetric strain increment for a change in isotropic stress $\Delta \sigma_{i}$. When computing conductivities, the cylindrical specimen is surrounded by non-conductive lateral boundaries. A longitudinal gradient is then imposed to generate the flux appropriate to the type of conductivity being considered. Conductivities are calculated as the ratio between the computed flux and the applied gradient.

[15] A complementary set of simulations is conducted for $20 \%$ hydrate-free sand patches embedded in a hydratesaturated sand host (i.e., $S_{h}=80 \%$ ).

\section{Physical Properties of a Patchy System: Results}

[16] We use the analytical models and numerical simulations described above to estimate the physical properties of hydrate-bearing sands with patchy-hydrate saturation. Table 4 lists the physical property values selected for these computations. These values correspond to hydrate-bearing sands with porosity $n=0.4$ and effective stress $\sigma^{\prime}=1 \mathrm{MPa}$.

\subsection{Bulk Modulus}

[17] Upper and lower bounds provide quick estimates to assess the plausibility of measured values. Parallel, series, and Hashin-Shtrikman bounds are shown in Figure 2 for the bulk modulus $K$ of hydrate-bearing sands, either assuming a threecomponent system (i.e., mineral, hydrate, and water) or a twocomponent patchy mixture (i.e., patches with $S_{h}=100 \%$ and sand with $S_{h}=0 \%$ ). The patchy saturation assumption significantly reduces the gap between upper and lower bounds because it removes the effect of extreme values for single components, such as the null shear stiffness of water in a series

Table 3a. Physical Properties: Analytical Estimates ${ }^{\mathrm{a}}$

\begin{tabular}{clc}
\hline Model & \multicolumn{1}{c}{ Equation } & Equation Number \\
\hline Kuster-Toksoz $^{\mathrm{b}}$ & $\left(K_{K T}-K_{m}\right) \frac{K_{m}+4 G_{m} / 3}{K_{K T}+4 G_{m} / 3}=\sum f_{i}\left(K_{i}-K_{m}\right) P_{m, i}$ & $\mathrm{~T} 5$ \\
& $\left(G_{K T}-G_{m}\right) \frac{G_{m}+4 \zeta_{m} / 3}{G_{K T}+4 \zeta_{m} / 3}=\sum f_{i}\left(G_{i}-G_{m}\right) Q_{m, i}$ & $\mathrm{~T} 6$ \\
Self-consistent $^{\mathrm{c}}$ & $0=\sum f_{i}\left(X_{i}-X\right) Z_{S C, i}$ & $\mathrm{~T} 7$ \\
\hline
\end{tabular}

\footnotetext{
${ }^{a}$ Analytical models for estimating, rather than bounding, the physical properties of gas hydrate-bearing sediment. $X$ is the estimated bulk property of the mixture. The terms $P_{m, i}, Q_{m, i}$, and $Z_{S C, i}$ depend on the patch shapes and physical properties, as expressed in Table $3 \mathrm{~b}$.

${ }^{\mathrm{b}}$ Kuster and Toksöz [1974].

${ }^{\mathrm{c}}$ Berryman [1980].
} 
Table 3b. Shape Factors for the Kuster-Toksoz $\left(P_{m, i}, Q_{m, i}\right)$ and Self-Consistent Models $\left(Z_{s c, i}\right)^{\mathrm{a}}$

\begin{tabular}{llll}
\hline & Spherical & Needle & Disk $^{\mathrm{b}}$ \\
\hline Conductivity $^{\mathrm{c}} Z_{s c, i}=$ & $\frac{1}{X_{i}+2 X_{m}}$ & $\frac{1}{9}\left(\frac{1}{X_{m}}+\frac{4}{X_{i}+X_{m}}\right)$ & $\frac{1}{9}\left(\frac{1}{X_{i}}+\frac{2}{X_{m}}\right)$ \\
Bulk modulus $Z_{s c, i}$ or $P_{m, i}=$ & $\frac{K_{m}+4 G_{m} / 3}{K_{i}+4 G_{m} / 3}$ & $\frac{K_{m}+G_{m}+G_{i} / 3}{K_{i}+G_{m}+G_{i} / 3}$ & $\frac{K_{m}+4 G_{i} / 3}{K_{i}+4 G_{i} / 3}$ \\
Shear modulus ${ }^{\mathrm{d}} Z_{s c, i}$ or $Q_{m, i}=$ & $\frac{G_{m}+\zeta_{m}}{G_{i}+\zeta_{m}}$ & $\frac{1}{5}\left(\frac{4 G_{m}}{G_{i}+G_{m}}+2 \frac{G_{m}+\vartheta_{m}}{G_{i}+\vartheta_{m}}+\frac{K_{i}+4 G_{m} / 3}{K_{i}+G_{m}+G_{i} / 3}\right)$ & $\frac{G_{m}+\zeta_{i}}{G_{i}+\zeta_{i}}$ \\
\hline
\end{tabular}

${ }^{\mathrm{a}}$ For $P_{m, i}$ and $Q_{m, i}$, the subscript $m$ refers to the property value for the maximum or minimum constituent, depending on whether the upper or lower bound is being calculated. For $Z_{s c, i}, m$ refers to the value for the final self-consistent material. In all cases, the subscript $i$ refers to the value for $i$ th component in the system [Berryman, 1995].

${ }^{b}$ Because of the $1 / X_{i}$ term, the disk approximation is calculated in Figure 4 (bottom) with a hydrate patch conductivity of $X_{i}=\left(1 \times 10^{-5}\right) \cdot X_{\text {hydrate-free patch }}$, rather than setting $X_{i}=0$.

${ }^{c}$ Appropriate for the conductivity, permeability, and permittivity properties listed in Table 3b. Though Berryman [1995] does not recommend this approach for hydraulic conductivity, equivalent relations have been derived specifically for hydraulic conductivity by Pozdniakov and Tsang [2004].

${ }^{d} \zeta_{m}=\frac{G_{m}}{6} \frac{9 K_{m}+8 G_{m}}{K_{m}+2 G_{m}}, \zeta_{i}=\frac{G_{i}}{6} \frac{9 K_{i}+8 G_{i}}{K_{i}+2 G_{i}}, \vartheta_{m}=G_{m} \frac{3 K_{m}+G_{m}}{3 K_{m}+7 G_{m}}, \vartheta_{i}=G_{i} \frac{3 K_{i}+G_{i}}{3 K_{i}+7 G_{i}}$.

configuration, or the high stiffness of quartz for a parallel arrangement (Table 4).

[18] Numerical simulations (solid dots in Figure 2) are obtained by assuming the host medium and inclusions are linearly elastic (values listed in Table 4). The numerically computed bulk modulus for hydrate-bearing sediments approaches the lower bound when the global hydrate saturation is low $\left(S_{h}<\sim 20 \%\right)$ and the upper bound when the global hydrate saturation is high $\left(S_{h}>\sim 80 \%\right)$. Moduli calculated from laboratory velocity measurements for various types of sediments containing THF hydrate reveal similar trends over a range of hydrate saturations [Lee et al., 2010].

[19] Numerical results show the increase in bulk stiffness of hydrate-bearing sediments with the number of hydratesaturated patches for a given hydrate saturation (Figure 2).
This result reflects interaction among patches as the number of patches increases and their relative distance becomes less than two times the patch size. Grain-based discrete-element simulations confirm that strong force chains form between large, hydrate-saturated sand patches [Jung et al., 2012]. Because the geometric distribution of patches in cylindrical specimens deviates from Hashin-Shtrikman assumptions, some numerical results fall outside the Hashin-Shtrikman bounds but remain within the series and parallel bounds.

[20] The Kuster-Toksöz effective media model compares well with finite element simulation results only when the patch concentration is low because the Kuster-Toksöz approach inherently disregards the collaborative coupling among inclusions, or patches, within the host material [see also Mavko et al., 1998]. The self-consistent model, in which

Table 4. Selected Physical Properties for Two- and Three-Component Mixtures in Hydrate-Bearing Sediment Systems (Assumed Porosity $n=0.4$ and Mean Effective Stress $\sigma_{\mathrm{v}}^{\prime}=1 \mathrm{MPa}$ )

\begin{tabular}{|c|c|c|c|c|c|}
\hline \multirow[b]{2}{*}{ Property } & \multicolumn{3}{|c|}{ Three-Component Mixture } & \multicolumn{2}{|c|}{ Two-Component Mixture } \\
\hline & Quartz & Seawater & Hydrate & Sediment + Seawater $\left(S_{h}=0 \%\right)$ & Sediment + Hydrate $\left(S_{h}=100 \%\right)$ \\
\hline Mass density $\rho\left(\mathrm{g} / \mathrm{cm}^{3}\right)$ & 2.65 & $1.02-1.05$ & 0.93 & 1.99 & 1.962 \\
\hline Poisson's ratio $\nu(-)$ & 0.17 & 0.5 & $0.33^{\mathrm{a}}$ & $0.15 \pm 0.05^{\mathrm{b}}$ & $0.3 \pm 0.05^{\mathrm{b}, \mathrm{c}}$ \\
\hline Shear wave velocity $V_{s}(\mathrm{~m} / \mathrm{s})$ & $4120^{\mathrm{n}}$ & 0 & $1960^{\mathrm{d}}$ & $392^{\mathrm{e}}$ & $1881^{\mathrm{e}}$ \\
\hline Compressional wave velocity $V_{p}(\mathrm{~m} / \mathrm{s})$ & $6040^{\mathrm{n}}$ & $1500^{\mathrm{n}}$ & $3770^{\mathrm{d}}$ & 1829 & 3065 \\
\hline Bulk modulus, $K(\mathrm{GPa})$ & $36.6^{\mathrm{n}}$ & $2.25^{\mathrm{n}}$ & $8.41^{\mathrm{n}}$ & $5.44^{\mathrm{p}}$ & $15.9^{\mathrm{p}}$ \\
\hline Shear modulus, $G(\mathrm{GPa})$ & $31.2^{\circ}$ & $0^{\mathrm{n}}$ & $3.54^{\mathrm{n}}$ & $0.27^{\mathrm{p}}$ & $7.3^{\mathrm{p}}$ \\
\hline Drained Young's Mod. E $E_{\text {drained }}(\mathrm{GPa})$ & 72 & 2.2 & $8.4^{\mathrm{a}}$ & 0.7 & 18.05 \\
\hline Thermal conductivity $\lambda(\mathrm{W} / \mathrm{m} / \mathrm{K})$ & $7.7-8.4^{\mathrm{f}}$ & $0.56^{\mathrm{g}}-0.58^{\mathrm{h}}$ & $0.5-0.58^{\mathrm{c}, \mathrm{i}, \mathrm{j}, \mathrm{k}}$ & $3.7^{\mathrm{j}}$ & $4.5^{\mathrm{j}}$ \\
\hline Heat capacity $C(\mathrm{~J} / \mathrm{kg} / \mathrm{K})$ & 730 & $4200^{\mathrm{h}}$ & $1980-2080^{\mathrm{a}, \mathrm{i}, 1, \mathrm{~m}}$ & 2118 & 1270 \\
\hline Hydraulic conductivity $k_{H}(\mathrm{~mm} / \mathrm{s})$ & 0 & $\mathrm{n} / \mathrm{a}$ & 0 & 0.1 & 0 \\
\hline Electrical conductivity $\sigma_{e}(\mathrm{~S} / \mathrm{m})$ & 0 & 5 & 0 & $1.15^{\mathrm{e}}$ & $0^{\mathrm{e}}$ \\
\hline Permittivity $\varepsilon_{r}(-)$ & 4.2 & 80 & 7 & $33^{\mathrm{e}}$ & $5^{e}$ \\
\hline
\end{tabular}

a Sloan and Koh [2008] (Methane hydrate).

${ }^{\mathrm{b}}$ Yun et al. [2005] (drained, skeleton, small strain).

${ }^{\mathrm{c}}$ Lee et al. [2010] (Methane hydrate, $263 \mathrm{~K}$ ).

${ }^{\mathrm{d}}$ Helgerud et al. [1999] (Methane hydrate, $5 \mathrm{MPa}, 273 \mathrm{~K}$ ).

${ }^{\mathrm{e}}$ Santamarina and Ruppel [2010].

${ }^{\mathrm{f}}$ Revil [2000].

${ }^{\mathrm{g}}$ Kaye and Laby [2008] (273 K).

${ }^{\mathrm{h}}$ Weast [1987] $(273 \mathrm{~K})$.

${ }^{\mathrm{i}}$ Waite et al. [2005] (THF hydrate, $261 \mathrm{~K}$ ).

${ }^{\mathrm{j}}$ Cortes et al. [2009] (THF hydrate, $261 \mathrm{~K}$ ).

${ }^{\mathrm{k}}$ Huang and Fan [2004].

${ }^{1}$ Handa et al. [1984].

${ }^{\mathrm{m}}$ Handa [1986] (Methane hydrate).

${ }^{\mathrm{n}}$ Waite et al. [2009].

${ }^{\circ}$ Peselnick et al. [1967].

${ }^{\mathrm{p}}$ Computed values. 


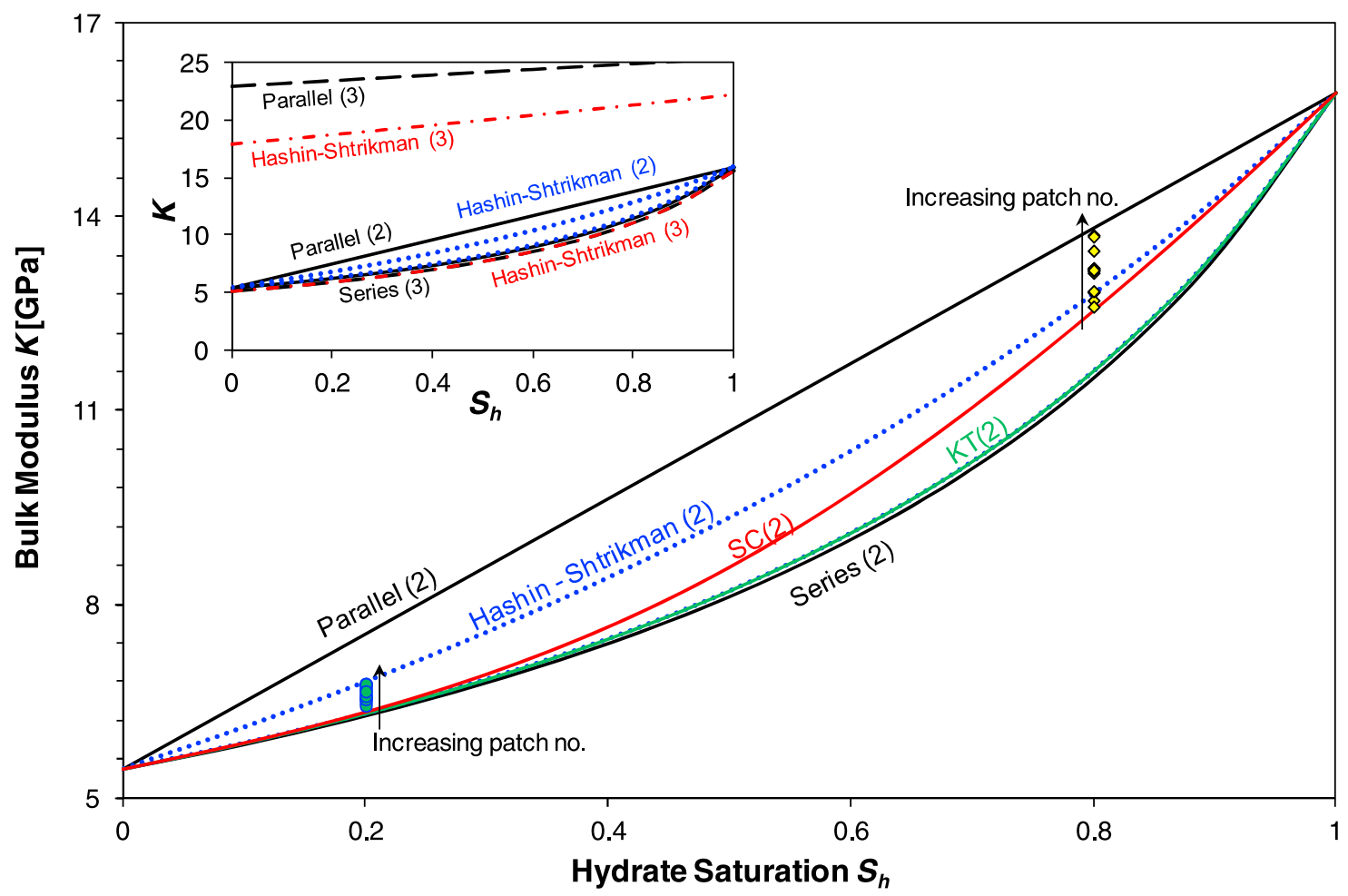

Two-component system

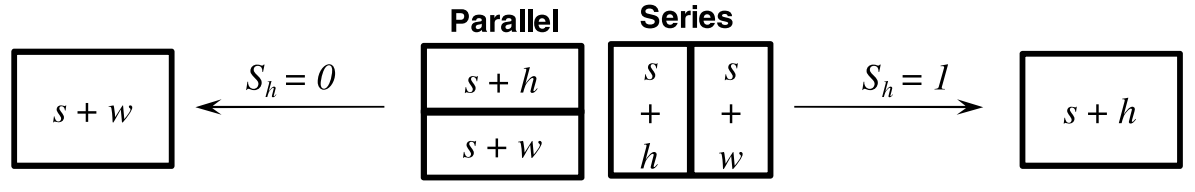

Three-component system

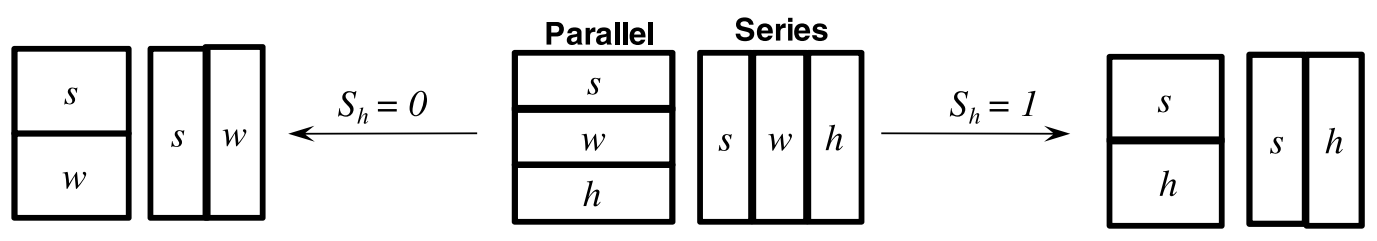

Figure 2. Bulk modulus $K$ : bounds, analytical models, and numerical simulations. Filled circles show numerical simulation results for a fixed hydrate saturation (either $S_{h}=0.2$ or 0.8 ) but different number of patches. KT: Kuster-Toksoz model; SC: self-consistent model. Numbers 2 and 3 after each model designate 2- and 3-component systems. The 2-component model bounds are significantly tighter than threecomponent bounds, a result that can be exploited when geologic conditions suggest 2-component patchy hydrate saturations can be expected rather than 3-component homogeneous hydrate distributions. Refer to Tables $2 \mathrm{a}$ and $2 \mathrm{~b}$ for material parameters and Tables $3 \mathrm{a}, 3 \mathrm{~b}$, and 4 for mathematical expressions.

all constituents are considered inclusions and there is no set host material, outperforms the Kuster-Toksöz model even at higher hydrate-patch concentrations [Berryman, 1980], in agreement with Figure 2.

\subsection{Thermal, Hydraulic and Electrical Conductivities}

[21] Conduction phenomena are mathematically equivalent. Therefore, the thermal, hydraulic, and electrical conductivities are estimated using the same analytical models
(Tables 3a and 3b), inserting the appropriate physical parameters for the property of interest (Table 4).

[22] Figure 3 shows that thermal, hydraulic, and electrical conductivities increase with the number of hydrate patches for a given hydrate saturation. Though measureable, this effect is small relative to the conductivity difference between hydrate-saturated patches and hydrate-free sediment, which is shown on the right side of each plot in Figure 3. At a fixed hydrate saturation, a single large patch inside the cylindrical specimen mimics the series (or Reuss) configuration. The 


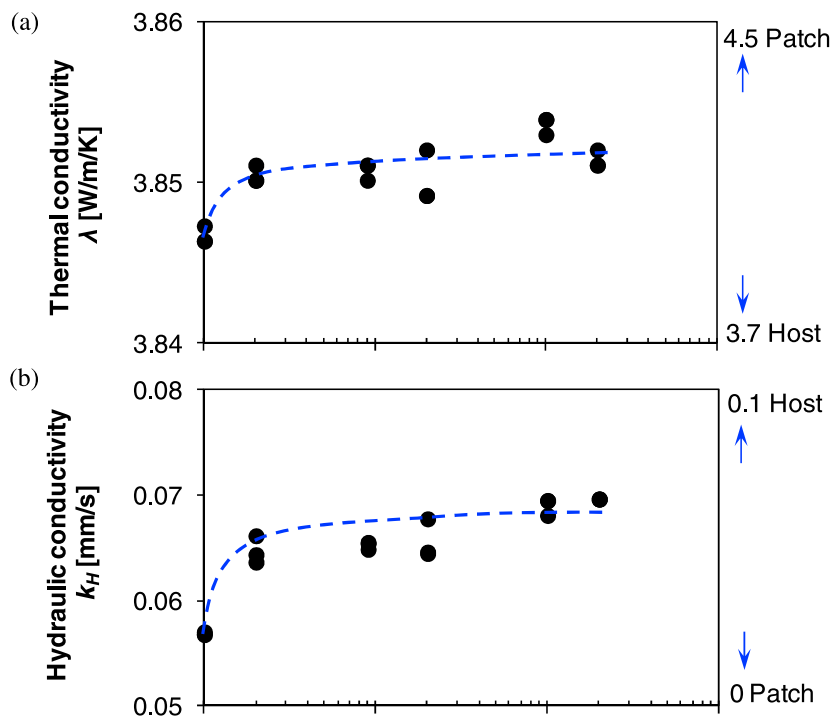

(c)

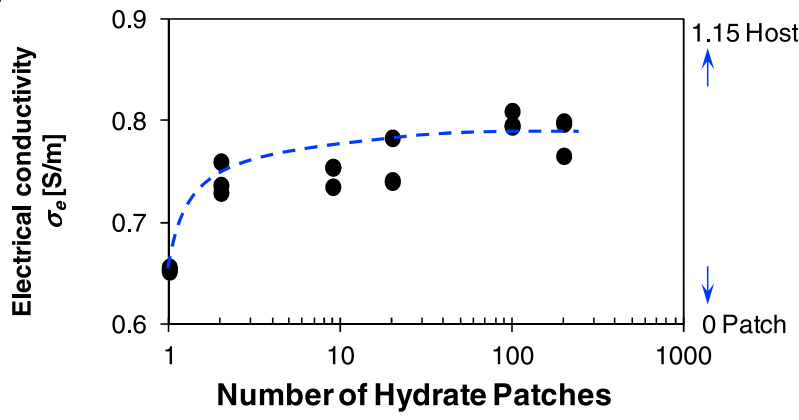

Figure 3. Conductivities versus the number of hydrate patches for a sandy specimen with porosity $n=0.4$ and hydrate saturation $S_{h}=0.2$. Dots are numerical results and dashed lines are trends. The patch size decreases as the number of patches increases to retain a constant hydrate saturation. The upper and lower end-member property values are given at the top and bottom right corner of each plot. Refer to Table 4 for material parameters.

size of each patch decreases when the number of patches increases at a fixed hydrate saturation and conduction improves as more flow paths become available.

\subsection{Discussion: Impact of Hydrate Pore Habit on Physical Properties}

\subsubsection{Compressional $P$ Wave Velocity}

[23] Figure 4 (top) shows trends with hydrate saturation for various growth patterns. A small amount of hydrate can dramatically increase the sediment stiffness, and hence the $P$ wave velocity, in "cementing systems" that form when water and gas phases are present (cases A and B - see experimental data in Priest et al. [2005, 2009] and a hybrid model in Chand et al. [2006]). This dramatic increase occurs because the gaswater interface clings onto water-wet minerals; then, when water converts to hydrate, the new solid phase dramatically stiffens contacts, increasing the $\mathrm{P}$ wave velocity even with only a small hydrate saturation. In contrast, there is no significant velocity increase at low hydrate saturations when hydrate forms from dissolved phase methane and nucleates either in the pore fluid $(\mathrm{C})$ or preferentially on mineral surfaces and grows away from grain contacts (D). Between $S_{h} \approx 25$ $40 \%$, enough hydrate forms to transition the pore nucleation case (C) to the structure-building case (D) as hydrate begins contacting more than one sediment grain within a pore and the velocity begins increasing rapidly with increasing hydrate saturation. The rapid stiffness increase in patchy distributions when hydrate saturation exceeds $30-40 \%$ results from increased patch size and enhanced interactions between patches (case E). This rapid increase has also been observed experimentally [Berge et al., 1999; Yun et al., 2005, 2007]. Cases A, B, C, and D are calculated using the formulation in Dvorkin et al. [2000] (equations also provided in Mavko et al. [1998]). In agreement with results in Figure 2, anticipated trends for patchy saturation (E) are estimated with the self-consistent model using the properties of hydrate-free host sediment and hydrate-saturated patches.

\subsubsection{Hydraulic Conductivity}

[24] Pore-filling hydrate leaves thin flow pathways which significantly reduce hydraulic conductivity (Figure 4, bottom, curve $\mathrm{H}_{1}$ ). More conductive, larger diameter flow paths exist in grain-coating hydrate (curve $\mathrm{H}_{2}$ ) [Kleinberg et al., 2003; Spangenberg, 2001]. Flow is effectively cut off in both of these homogeneous distribution cases by $S_{h}=80 \%$. Concentrating hydrate into spherical or needle-shaped hydrate saturated patches leaves hydrate-free sections; hence, spherical and needleshaped patches are less disruptive to fluid flow than homogeneous hydrate distributions (curves $\mathrm{P}_{2}$ and $\mathrm{P}_{3}$ ). Disk-shaped patches aligned normal to flow can cause extreme flow-blocking conditions even at low hydrate saturations (curve $\mathrm{P}_{1}$ ). Conversely, high patch aspect ratio in the flow direction lowers the impact of non-conductive patches on global conductivity [Xia and Thrope, 1988]. Spherical patches exhibit a conductivity cutoff at a percolation threshold $S_{h}=2 / 3$; for higher hydrate saturation, the needle-shaped patch in the selfconsistent model (i.e., curve $\mathrm{P}_{3}$ ) may better represent field conditions [Berryman, 1995].

[25] The analysis based on patchy saturation can also be applied to natural hydrate-bearing fines where lenses or chunks are made of $100 \%$ segregated hydrate, with the caveat that anisotropy can control such systems. Conductivities can become patch shape- and orientation- dependent, as has been observed in recent gas hydrate logging studies in fine-grained sediments [Cook et al., 2008; Lee and Collett, 2009].

\section{Conclusions}

[26] The lithologically determined and spatially varying hydraulic conductivity in sediments control advective methane transport and the reservoir-scale heterogeneous hydrate distribution [Nimblett and Ruppel, 2003; Weinberger and Brown, 2006]. Yet, hydrate morphology at the meso-scale is inherently controlled by the state of effective stress $\sigma^{\prime}$ and the grain size of the finer fraction of the sediment $d_{10}$. Therefore, the meso-scale hydrate morphology can be anticipated from burial depth and sediment type.

[27] Heterogeneous hydrate distributions can be grouped into (1) hydrate-water capillarity-controlled grain-displacing nodules and chunks in fine-grained sediments at low effective stress, (2) lenses and veins in fine-grained sediments at intermediate effective stress where hydrate-water capillarity and effective stress affect growth, and (3) patchy saturation 


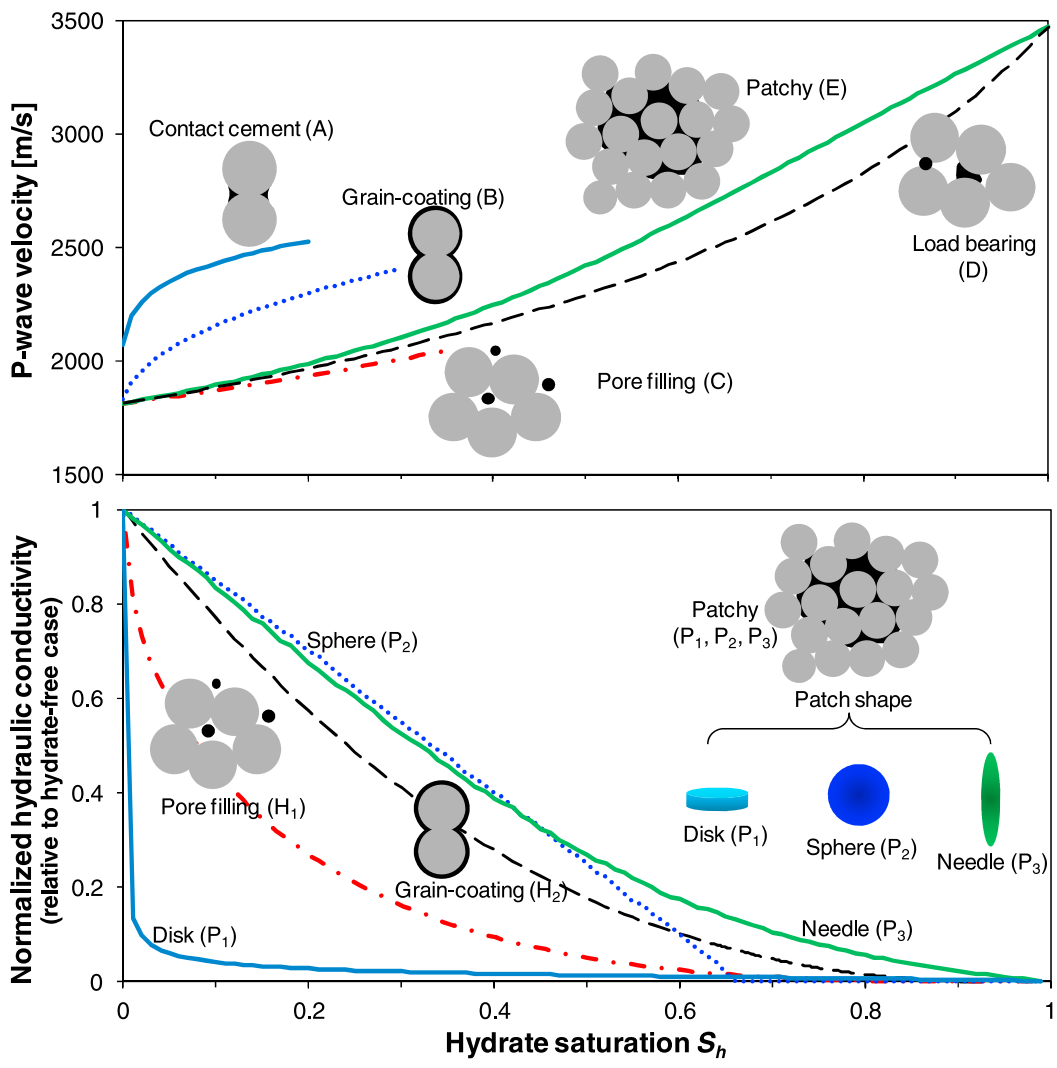

Figure 4. Self-consistent versus pore-habit specific models: predicted dependence of physical properties on gas hydrate saturation. (top) Compressional, $\mathrm{P}$ wave velocity: $\mathrm{P}$ wave velocity increases rapidly even at very low hydrate saturations when hydrate forms at sediment grain contacts. When hydrate forms away from grain contacts $(\mathrm{C}, \mathrm{D})$, the velocity increases more rapidly at high hydrate saturation when hydrate begins bridging between multiple sediment grains across a pore or fully hydrate-saturated patches become large and numerous enough to begin interacting (E). Hydrate contacts sediment grains and can no longer be considered purely part of the pore fluid above $S_{h} \approx 25-40 \%$. (bottom) Normalized hydraulic conductivity relative to the hydrate-free $S_{h}=0$ state: homogeneous hydrate distributions including pore-filling $\left(\mathrm{H}_{1}\right)$ or grain coating $\left(\mathrm{H}_{2}\right)$ hydrates versus patchy hydrate distributions with disk- $\left(\mathrm{P}_{1}\right)$, sphere- $\left(\mathrm{P}_{2}\right)$, or needle- shaped $\left(\mathrm{P}_{3}\right)$ hydrates. Homogeneous curves $\mathrm{H}_{1}$ and $\mathrm{H}_{2}$ are calculated from Kleinberg et al. [2003]. Patchy distribution curves $\mathrm{P}_{1}, \mathrm{P}_{2}$, and $\mathrm{P}_{3}$ are calculated from Table 4 [Berryman, 1995; Pozdniakov and Tsang, 2004].

in coarse sands at high effective stress where the granular skeleton remains unaltered during hydrate growth.

[28] Hydrate-bearing sands are of particular interest as an energy resource. Accounting for patchy saturation, hydratebearing sands can be analyzed as a two-component system made of hydrate-saturated sand patches $\left(S_{h}=100 \%\right)$ embedded in hydrate-free sand $\left(S_{h}=0 \%\right)$. This morphology can be exploited to tighten the bounds of potential physical property values relative to bounds obtained by assuming homogeneous multicomponent mixtures of mineral-hydrategas or mineral-hydrate-gas-water.

[29] The bulk stiffness of patchy hydrate-bearing sands approaches the lower Voigt-Reuss bound at low hydrate saturations and the upper bound at high saturations due to the mechanical interaction between hydrate-saturated patches. The self-consistent model tracks this shift from the lower-bound to the upper-bound with increasing hydrate saturation, unlike many morphology-specific models that tend to follow either the lower or upper-bound over the entire saturation range.
[30] Patchy hydrate saturation is generally less disruptive to bulk conductivities than homogeneously distributed hydrates. Smaller patches increase flow tortuosity but have lower possibility of extreme flow-blocking conditions. An increased patch slenderness in the fluid flow direction decreases the impact of patches on the global sediment conductivity.

\section{Notation}

$u_{h}$ pressure in the hydrate phase, $\mathrm{Pa}$.

$u_{w}$ pressure in the water phase, $\mathrm{Pa}$.

$\sigma^{\prime}$ effective stress, $\mathrm{Pa}$.

$\gamma_{w h}$ the hydrate-water interfacial tension, $\mathrm{N} \mathrm{m}^{-1}$.

$\theta$ contact angle, degrees.

$d_{c r}$ minimum crystal size, $\mathrm{m}$.

$d_{\text {th }}$ pore throat diameter, $\mathrm{m}$.

$d_{10}$ the finest 10th percentile in the grain size distribution, $\mathrm{m}$.

$\Psi$ defined dimensionless stress parameter.

$S_{h}$ hydrate saturation.

$R$ radius, $\mathrm{m}$. 
$H$ height, $\mathrm{m}$.

$n$ porosity.

$E$ Young's modulus, $\mathrm{Pa}$.

$\sigma_{i}$ isotropic stress, $\mathrm{Pa}$.

$\varepsilon_{v}$ volumetric strain.

$\lambda$ thermal conductivity, $\mathrm{W} \mathrm{m}^{-1} \mathrm{~K}^{-1}$.

$k_{H}$ hydraulic conductivity, $\mathrm{m} \mathrm{s}^{-1}$.

$\sigma_{e}$ electric conductivity, $\mathrm{S} \mathrm{m}^{-1}$.

$\rho$ mass density, $\mathrm{kg} \mathrm{m}^{-3}$.

$v$ Poison's ratio.

$V_{s}$ shear wave velocity, $\mathrm{m} \mathrm{s}^{-1}$.

$V_{p}$ compressional wave velocity, $\mathrm{m} \mathrm{s}^{-1}$.

$K$ bulk modulus, $\mathrm{Pa}$.

$G$ shear modulus, $\mathrm{Pa}$.

$E_{\text {drained }}$ drained Young's modulus, $\mathrm{Pa}$.

$C$ heat capacity, $\mathrm{J} \mathrm{kg}^{-1} \mathrm{~K}^{-1}$.

$\varepsilon_{r}$ dielectric permittivity.

$\mu$ magnetic permeability.

$f_{i}$ volume fraction of composite $i$.

$L L$ liquid limit.

$P L$ plastic limit.

Ss specific surface, $\mathrm{m}^{2} / \mathrm{g}$.

$\phi$ the phi scale of particle size.

$S$ sorting.

Sk skewness.

$K t$ kurtosis.

$X$ bulk properties.

$x$ component properties.

$\alpha, \xi$ coefficients in Hashin-Shtrikman model, refer to Tables $2 \mathrm{a}$ and $2 \mathrm{~b}$.

$P, Q, \zeta, v$ coefficients in Kuster-Toksoz model, refer to Tables $3 \mathrm{a}$ and $3 \mathrm{~b}$.

$Z, \zeta, v$ coefficients in self-consistent model, refer to Tables $3 \mathrm{a}$ and $3 \mathrm{~b}$.

[31] Acknowledgments. Research support provided to Georgia Tech by the Department of Energy/JIP project for methane hydrate, administered by Chevron. Additional funding provided by the Goiuzeta Foundation, the Gas Hydrate Project of the U.S. Geological Survey's Coastal and Marine Geology Program, and the Assistant Secretary for Fossil Energy, Office of Oil and Natural Gas, Gas Hydrate Program through the National Energy Technology Laboratory of the U.S. Department of Energy under contract DE-AC02-05CH11231. Any use of trade names is for descriptive purposes only and does not imply endorsement by the U.S. Government.

\section{References}

Anderson, R., M. Llamedo, B. Tohidi, and R. W. Burgass (2003), Experimental measurement of methane and carbon dioxide clathrate hydrate equilibria in mesoporous silica, J. Phys. Chem. B, 107, 3507-3514.

Asami, K. (2005), Simulation of dielectric relaxation in periodic binary systems of complex geometry, J. Colloid Interface Sci., 292(1), 228-235, doi:10.1016/j.jcis.2005.05.076.

Berge, L. I., K. A. Jacobsen, and A. Solstad (1999), Measured acoustic wave velocities of $\mathrm{R} 11(\mathrm{CCl} 3 \mathrm{~F})$ hydrate samples with and without sand as a function of hydrate concentration, J. Geophys. Res., 104(B7), 15,415-15,424, doi:10.1029/1999JB900098.

Berryman, J. G. (1980), Long-wavelength propagation in composite elastic media I. Spherical inclusions, J. Acoust. Soc. Am., 68, 1809-1819, doi:10.1121/1.385171.

Berryman, J. G. (1995), Mixture theories for rock properties, in Rock Physics and Phase Relations: A Handbook of Physical Constants, AGU Ref Shelf, vol. 3, edited by T. J. Ahrens, pp. 205-228, AGU, Washington, D. C., doi:10.1029/RF003p0205.

Boswell, R. D., D. Shelander, M. Lee, T. Latham, T. Collett, G. Guerin G. Moridis, M. Reagan, and D. Golberg (2009), Occurrence of gas hydrate in Oligocene Frio Sand: Alaminos Canyon Block 818: North Gulf of Mexico, Mar. Pet. Geol., 26, 1499-1512, doi:10.1016/j.marpetgeo.2009.03.005.
Bryant, W., A. Wetzel, and W. Sweet (1986), Geotechnical properties of intraslope basin sediments, Gulf of Mexico, Deep Sea Drilling Project Leg 96, Site 619, Initial Rep. Deep Sea Drill. Proj., 96, 819-824.

Buffett, B., and D. Archer (2004), Global inventory of methane clathrate: Sensitivity to changes in the deep ocean, Earth Planet. Sci. Lett., 227 185-199, doi:10.1016/j.epsl.2004.09.005.

Camerlenghi, A., R. G. Lucchi, and R. G. Rothwell (1995), Grain-size analysis and distribution in Cascadia Margin sediments, northeastern Pacific, Proc. Ocean Drill. Program Sci. Results, 146, 3-31.

Chand, S., T. A. Minshull, J. A. Priest, A. I. Best, C. R. I. Clayton, and W. F. Waite (2006), An effective medium inversion algorithm for gas hydrate quantification and its application to laboratory and borehole measurements of gas hydrate-bearing sediments, Geophys. J. Int., 166 , 543-552, doi:10.1111/j.1365-246X.2006.03038.x.

Clennell, M. B., M. Hovland, J. S. Booth, P. Henry, and W. J. Winters (1999), Formation of natural gas hydrates in marine sediments 1. Conceptual model of gas hydrate growth conditioned by host sediment properties, J. Geophys. Res., 104(B10), 22,985-23,003, doi:10.1029/ 1999JB900175.

Collett, T. S., and R. F. Wendlandt (2000), Formation evaluation of gas hydrate-bearing sediments on the Blake Ridge with downhole geochemical log measurements, Proc. Ocean Drill. Program Sci. Results, 164, 199-215.

Collett, T. S., M. Riedel, J. R. Cochran, R. Boswell, P. Kumar, and A. V. Sathe (2008), Indian continental margin gas hydrate prospects; results of the Indian National Gas Hydrate Program (NGHP) Expedition 01 , paper presented at 6th International Conference on Gas Hydrates, Chevron, Vancouver, B. C., Canada, 6-10 July.

Collett, T. S., A. H. Johnson, C. C. Knapp, and R. Boswell (2009), Natural Gas Hydrates: A Review, in Natural Gas Hydrates-Energy Resource Potential and Associated Geologic Hazards, edited by T. Collett et al., AAPG Mem., 89, 146-219.

Cook, A., D. Goldberg, and R. L. Kleinberg (2008), Fracture-controlled gas hydrate systems in the northern Gulf of Mexico, Mar. Pet. Geol., 25 , 932-941, doi:10.1016/j.marpetgeo.2008.01.013.

Cortes, D. D., A. I. Martin, T. S. Yun, F. M. Francisca, J. C. Santamarina, and C. Ruppel (2009), Thermal conductivity of hydrate-bearing sediments, J. Geophys. Res., 114, B11103, doi:10.1029/2008JB006235.

Coussy, O. (2010), Mechanics and Physics of Porous Solids, 296 pp., John Wiley, Chichester, U. K., doi:10.1002/9780470710388.

Dai, S., C. Lee, and J. C. Santamarina (2011), Formation history and physical properties of sediments from the Mount Elbert Gas Hydrate Stratigraphic Test Well, Alaska North Slope, Mar. Pet. Geol., 28(2), 427-438, doi:10.1016/j.marpetgeo.2010.03.005.

Daigle, H., and B. Dugan (2010), Origin and evolution of fracture-hosted methane hydrate deposits, J. Geophys. Res., 115, B11103, doi:10.1029/ $2010 J B 007492$.

Dang, H., X. W. Luan, R. Chen, X. Zhang, L. Guo, and M. G. Klotz (2010), Diversity, abundance and distribution of amoA-encoding archaea in deepsea methane seep sediments of the Okhotsk Sea, Federation of European Microbiological Societies, Microb. Ecol., 72, 370-385, doi:10.1111/ j.1574-6941.2010.00870.x

Dominguez, A., S. Bories, and M. Prat (2000), Gas cluster growth by solute diffusion in porous media. Experiments and automation simulation on pore network, Int. J. Multiphase Flow, 26, 1951-1979, doi:10.1016/ S0301-9322(00)00006-9.

Dvorkin, J., and A. Nur (1998), Acoustic signatures of patchy saturation, Int. J. Solids Struct., 35(34-35), 4803-4810, doi:10.1016/S0020-7683 (98)00095-X

Dvorkin, J., M. B. Helgerud, W. F. Waite, S. H. Kirby, and A. Nur (2000), Introduction to physical properties and elasticity models, in Natural Gas Hydrate in Oceanic and Permafrost Environments, edited by M. D. Max, pp. 245-260, Kluwer Acad., Dordrecht, Netherlands, doi:10.1007/97894-011-4387-5 20

Ersland, G., J. Husebo, A. Graue, B. A. Baldwin, J. Howard, and J. Stevens (2010), Measuring gas hydrate formation and exchange with $\mathrm{CO}_{2}$ in Bentheim sandstone using MRI tomography, Chem. Eng. J., 158, 25-31, doi:10.1016/j.cej.2008.12.028.

Gornitz, V., and I. Fung (1994), Potential distribution of methane hydrates in the world's oceans, Global Biogeochem. Cycles, 8, 335-347, doi:10.1029/94 GB00766.

Handa, Y. P. (1986), Compositions, enthalpies of dissociation, and heat capacities in the range 85 to $270 \mathrm{~K}$ for clathrate hydrates of methane, ethane, and propane, and enthalpy of dissociation of isobutane hydrate, as determined by a heat-flow calorimeter, J. Chem. Thermodyn., 18,915-921, doi:10.1016 00219614(86)90149-7.

Handa, Y. P., R. E. Hawkins, and J. J. Murray (1984), Calibration and testing of a Tian-Calvet heat flow calorimeter. Enthalpies of fusion and heat 
capacities for ice and THF hydrate in the range 85 to $270 \mathrm{~K}$, J. Chem. Thermodyn., 16, 623-632, doi:10.1016/0021-9614(84)90042-9.

Harter, T., and C. Knudby (2004), Effective conductivity of periodic media with cuboid inclusions, Adv. Water Resour., 27, 1017-1032, doi:10.1016/ j.advwatres.2004.07.004.

Hashin, Z., and S. Shtrikman (1962), A variational approach to the theory of the effective magnetic permeability of multiphase materials, J. Appl. Phys., 33, 3125-3131, doi:10.1063/1.1728579.

Hashin, Z., and S. Shtrikman (1963), A variational approach to the theory of the elastic behavior of multiphase materials, J. Mech. Phys. Solids, 11, 127-140, doi:10.1016/0022-5096(63)90060-7.

Helgerud, M. B., J. Dvorkin, A. Nur, A. Sakai, and T. Collett (1999), Elastic-wave velocity in marine sediments with gas hydrates: Effective medium modeling, Geophys. Res. Lett., 26, 2021-2024, doi:10.1029/ 1999GL900421.

Henry, P., M. Thomas, and M. B. Clennell (1999), Formation of natural gas hydrate in marine sediments: 2 . Thermodynamic calculations of stability conditions in porous sediments, J. Geophys. Res., 104, 23,005-23,022, doi:10.1029/1999JB900167.

Hill, P. R., and J. C. Marsters (1990), Controls on physical properties of Peru continental margin sediments and their relationship to deformation styles, Proc. Ocean Drill. Program Sci. Results, 112, 623-632.

Holland, M., P. Schultheiss, J. Roberts, and M. Druce (2008), Observed gas hydrate morphologies in marine sediments, paper presented at 6th International Conference on Gas Hydrates, Chevron, Vancouver, B. C. Canada, 6-10 July.

Holler, P. R. (1992), Consolidation characteristics and permeabilities of sediments from Japan Sea (Sites 798 and 799), Proc. Ocean Drill. Program Sci. Results, 127/128, 1123-1133.

Hovland, M., D. Lysne, and M. Whiticar (1995), Gas hydrate and sediment gas composition, Hole 892A, Proc. Ocean Drill. Program Sci. Results 146, 151-161.

Huang, D., and S. Fan (2004), Thermal conductivity of methane hydrate formed from sodium dodecyl sulfate solution, J. Chem. Eng. Data, 49 1479-1482, doi:10.1021/je0498098.

Jin, S., J. Nagao, S. Takeya, Y. Jin, J. Hayashi, Y. Kamata, T. Ebinuma, and H. Narita (2006), Structural investigation of methane hydrate sediments by microfocus X-ray computed tomography technique under high-pressure conditions, Jpn. J. Appl. Phys., 45, L714-L716, doi:10.1143/JJAP.45.L714.

Jung, J. W., J. C. Santamarina, and K. Soga (2012), Stress-strain response of hydrate-bearing sands: Numerical study using discrete element method simulations, J. Geophys. Res., 117, B04202, doi:10.1029/2011JB009040.

Kaye and Laby (2008), Tables of physical and chemical constants, Natl Phys. Lab., Teddington, U. K. [Available at http://www.kayelaby.npl. co.uk/]

Kerkar, P., K. W. Jones, R. Kleinberg, W. B. Lindquist, S. Tomov, H. Feng, and D. Mahajan (2009), Direct observations of three dimensional growth of hydrates hosted in porous media, Appl. Phys. Lett., 95, 024102 , doi:10.1063/1.3120544

Kim, G. Y., B. Y. Yi, D. G. Yoo, B. J. Ryu, and M. Riedel (2011), Evidence of gas hydrate from downhole logging data in the Ulleung Basin, East Sea, Mar. Pet. Geol., 28(10), 1979-1985, doi:10.1016/j.marpetgeo. 2011.01.011.

Kleinberg, R. L., C. Flaum, D. D. Griffin, P. G. Brewer, G. E. Malby, E. T Peltzer, and J. P. Yesinowski (2003), Deep sea NMR: Methane hydrate growth habit in porous media and its relationship to hydraulic permeability, deposit accumulation, and submarine slope stability, J. Geophys. Res., 108(B10), 2508, doi:10.1029/2003JB002389.

Kneafsey, T. J., H. Lu, W. Winters, R. Boswell, R. Hunter, and T. S. Collett (2010), Analysis of core samples from the BPXA-DOE-USGS Mount Elbert gas hydrate stratigraphic test well: Insights into core disturbance and handling, Mar. Pet. Geol., 28(2), 381-393, doi:10.1016/j.marpetgeo. 2009.10.009.

Knight, R., and R. Nolenhoeksema (1990), A laboratory study of the dependence of elastic wave velocities on pore scale fluid distribution, Geophys. Res. Lett., 17(10), 1529-1532, doi:10.1029/GL017i010p01529.

Kulenkampff, J., and E. Spangenberg (2005), Physical properties of cores from the JAPEX/JNOC/GSC et al. Mallik $5 \mathrm{~L}-38$ gas hydrate production research well under simulated in situ conditions using the Fielding Laboratory Experimental Core Analysis System (FLECAS), in Scientific Results from the Mallik 2002 Gas Hydrate Production Research Well Program, Mackenzie Delta, Northwest Territories, Canada, edited by S. R. Dallimore and T. S. Collett, Bull. Geol. Surv. Can., 585, 1-16.

Kuster, G. T., and M. N. Toksöz (1974), Velocity and attenuation of seismic waves in two-phase media: Part 1. Theoretical formulations, Geophysics, 59, 587-606.
Kvenvolden, K. A., and M. Kastner (1990), Gas hydrates of the Peruvian outer continental margin, Proc. Ocean Drill. Program Sci. Results, 112 517-526.

Kwon, T.-H., G.-C. Cho, and J. C. Santamarina (2008), Gas hydrate dissociation in sediments: Pressure-temperature evolution, Geochem. Geophys. Geosyst., 9, Q03019, doi:10.1029/2007GC001920.

Kwon, T. H., K. R. Lee, G. C. Cho, and J. Y. Lee (2011), Geotechnical properties of deep oceanic sediments recovered from the hydrate occurrence regions in the Ulleung Basin, Offshore Korea, Mar. Pet. Geol. 28(10), 1870-1883, doi:10.1016/j.marpetgeo.2011.02.003.

Lee, J. Y. (2007), Hydrate-bearing sediments: Formation and geophysical properties, $\mathrm{PhD}$ thesis, $\mathrm{Ga}$. Inst. of Technol., Atlanta.

Lee, J. Y., F. M. Francisca, J. C. Santamarina, and C. Ruppel (2010), Parametric study of the physical properties of hydrate-bearing sand, silt, and clay sediments: 2. Small-strain mechanical properties, J. Geophys. Res., 115, B11105, doi:10.1029/2009JB006670.

Lee, M. W., and T. S. Collett (2009), Gas hydrate saturations estimated from fractured reservoir at Site NGHP-01-10, Krishna-Godavari Basin, India, J. Geophys. Res., 114, B07102, doi:10.1029/2008JB006237, 13 p. Li, X., L. Zhong, and L. J. Pyrak-Nolte (2001), Physics of partially saturated porous media: Residual saturation and seismic-wave propagation, Annu. Rev. Earth Planet. Sci., 29, 419-460, doi:10.1146/annurev.earth. 29.1.419.

Luan, X., Y. Jin, A. Obzhirov, and B. Yue (2008), Characteristics of shallow gas hydrate in Okhotsk Sea, Sci. China, Ser. D Earth Sci., 51(3), 415-421.

Matsumoto, R., T. Uchida, A. Waseda, T. Uchida, S. Takeya, T. Hirano, K. Yamada, Y. Maeda, and T. Okui (2000), Occurrence, structure, and composition of natural gas hydrate recovered from the Blake Ridge, Northwest Atlantic, Proc. Ocean Drill. Program Sci. Results, 164, 13-28.

Mavko, G., and T. Mukerji (1998), Bounds on low-frequency seismic velocities in partially saturated rocks, Geophysics, 63(3), 918-924.

Mavko, G., T. Mukerji, and J. Dvorkin (1998), The Rock Physics Handbook: Tools for Seismic Analysis in Porous Media, 329 pp., Cambridge Univ. Press, Cambridge, U. K.

McIver, R. D. (1981), Gas hydrates, in Long Term Energy Resources, edited by R. F. Meyer and J. C. Olson, pp. 713-726, Pitman, Boston, Mass Milkov, A. (2004), Global estimates of hydrate-bound gas in marine sediments: How much is really out there?, Earth Sci. Rev., 66, 183-197, doi:10.1016/j.earscirev.2003.11.002.

Myerson, A. S. (2002), Handbook of Industrial Crystallization, 2nd ed. Butterworth-Heinemann, Boston.

Nimblett, J., and C. Ruppel (2003), Permeability evolution during the formation of gas hydrates in marine sediments, J. Geophys. Res., 108(B9), 2420, doi:10.1029/2001JB001650.

Page, A. J., and R. P. Sear (2006), Heterogeneous nucleation in and out of pores, Phys. Rev. Lett., 97(6), 065701, doi:10.1103/PhysRevLett.97. 065701

Peselnick, L., R. Meister, and W. H. Wilson (1967), Pressure derivatives of elastic moduli of fused quartz to $10 \mathrm{~kb}, J$. Phys. Chem. Solids, 28, 635-639, doi:10.1016/0022-3697(67)90094-7.

Pflaunm, R. C., J. M. Brooks, H. B. Cox, M. C. Kennicutt II, and D. D. Sheu (1985), Molecular and isotopic analysis of core gases and gas hydrates, Initial Rep. Deep Sea Drill. Proj., 96, 781-784.

Phadnis, H. S., and J. C. Santamarina (2011), Bacteria in sediments: Pore size effects, Geotech. Lett., 1(4), 91-93, doi:10.1680/geolett.11.00008.

Pozdniakov, S., and C.-F. Tsang (2004), A self-consistent approach for calculating the effective hydraulic conductivity of a binary, heterogeneous medium, Water Resour. Res., 40, W05105, doi:10.1029/2003WR002617.

Priest, J. A., A. I. Best, and C. R. I. Clayton (2005), A laboratory investigation into the seismic velocities of methane gas hydrate-bearing sand J. Geophys. Res., 110, B04102, doi:10.1029/2004JB003259.

Priest, J. A., E. V. L. Rees, and C. R. I. Clayton (2009), Influence of gas hydrate morphology on the seismic velocities of sands, J. Geophys. Res., 114, B11205, doi:10.1029/2009JB006284.

Quintal, B., M. Frehner, C. Madonna, N. Tisato, M. Kuteynikova, and E. H. Saenger (2011), Integrated numerical and laboratory rock physics applied to seismic characterization of reservoir rocks, Leading Edge, 30(12), 1360-1367, doi:10.1190/1.3672480.

Revil, A. (2000), Thermal conductivity of unconsolidated sediments with geophysical applications, J. Geophys. Res., 105, 16,749-16,768, doi:10.1029/2000JB900043.

Santamarina, J. C., and C. Ruppel (2010), The impact of hydrate saturation on the mechanical, electrical, and thermal properties of hydrate-bearing sand, silts, and clay, in Geophysical Characterization of Gas Hydrates, SEG Geophys. Dev. Ser., vol. 14, edited by M. Riedel, E. Willoughby, and S. Chopra, pp. 373-383, Soc. of Explor. Geophys., Tulsa, Okla. 
Shankar, U., and M. Riedel (2011), Gas hydrate saturation in the KrishnaGodavari basin from P-wave velocity and electrical resistivity logs, Mar. Pet. Geol., 28(10), 1768-1778.

Shin, H., and J. C. Santamarina (2011), Opening mode discontinuities in soils, Geotech. Lett., 1, 95-99.

Sloan, E. D., and C. A. Koh (2008), Clathrate Hydrates of Natural Gases, 3rd ed., 721 pp., CRC Press, Boca Raton, Fla.

Spangenberg, E. (2001), Modeling of the influence of gas hydrate content on the electrical properties of porous sediments, J. Geophys. Res., 106(B4), 6535-6548, doi:10.1029/2000JB900434.

Stern, L. A., T. D. Lorenson, and J. C. Pinkston (2011), Gas hydrate characterization and grain-scale imaging of recovered cores from the Mount Elbert Gas Hydrate Stratigraphic Test Well, Alaska North Slope, Mar. Pet. Geol., 28(2), 394-403, doi:10.1016/j.marpetgeo.2009.08.003.

Stevens, J. C., B. A. Baldwin, A. Graue, G. Ersland, J. Husebe, and J. J. Howard (2008), Measurements of hydrate formation in sandstone, Petrophysics, 49(1), 67-73.

Taira, A., et al. (1991), Proceedings of the Ocean Drilling Program, Initial Reports, vol. 131, pp. 71-269, Ocean Drill. Program, College Station, Tex.

Tamaki, K., et al. (1990), Proceedings of the Ocean Drilling Program, Initial Reports, vol. 127, Ocean Drill. Program, College Station, Tex.

Tan, B., J. T. Germaine, and P. B. Flemings (2006), Data report: Consolidation and strength characteristics of sediments from ODP Site 1244 Hydrate Ridge, Cascadia continental margin, Proc. Ocean Drill. Program Sci. Rep., 204, 148 pp.

Thayer, P. A., H. H. Roberts, A. H. Bouma, and J. M. Coleman (1986), Sedimentology and petrology of Mississippi Fan depositional environments, Initial Rep. Deep Sea Drill. Proj., 96, 489-503.

Tohidi, B., R. Anderson, M. B. Clennell, R. W. Burgass, and A. B. Biderkab (2001), Visual observation of gas-hydrate formation and dissociation in synthetic porous media by means of glass micromodels, Geology, 29(9), 867-870, doi:10.1130/0091-7613(2001)029<0867:VOOGHF>2.0.CO;2.

Trofimuk, A. A., N. V. Cherskiy, and V. P. Tsarev (1973), Accumulation of natural gases in zones of hydrate-formation in the hydrosphere [in Russian], Dokl. Akad. Nauk SSSR, 212, 931-934.

Uchida, T., T. Ebinuma, and T. Ishizaki (1999), Dissociation condition measurements of methane hydrate in confined small pores of porous glass, J. Phys. Chem. B, 103, 3659-3662, doi:10.1021/jp9845591.

Uchida, T., S. Dallimore, and J. Mikami (2000), Occurrences of natural gas hydrates beneath the permafrost zone in Mackenzie Delta: Visual and X-ray CT imagery, Ann. N. Y. Acad. Sci., 912(1), 1021-1033, doi:10.1111/ j.1749-6632.2000.tb06857.x.

Uchida, T., H. Long, H. Tomaru, and the MITI Nankai Trough Shipboard Scientists (2004), Subsurface Occurrence of natural gas hydrate in the Nankai Trough area: Implication for gas hydrate concentration, Resour. Geol., 54(1), 35-44, doi:10.1111/j.1751-3928.2004.tb00185.x.

Vogelaar, B., D. Smeulders, and J. Harris (2010), Exact expression for the effective acoustics of patchy-saturated rocks, Geophysics, 75(4), N87-N96.

von Huene, R. V., E. Suess, and K. C. Emeis (1987), Ocean Drilling Program Leg 112 Preliminary Report, Peru Continental Margin, Ocean Drill. Program, College Station, Tex.

Waite, W. F., W. J. Winters, and D. H. Mason (2004), Methane hydrate formation in partially water-saturated Ottawa sand, Am. Mineral., 89(8-9), 1202-1207

Waite, W. F., L. Y. Gilbert, W. J. Winters, and D. H. Mason (2005), Thermal property measurements in tetrahydrofuran (THF) hydrate and hydrate- bearing sediment between -25 and $+4^{\circ} \mathrm{C}$, and their application to methane hydrate, in Fifth International Conference on Gas Hydrates, pp. 1724-1733, Tapir Acad., Trondheim, Norway.

Waite, W. F., et al. (2009), Physical properties of hydrate-bearing sediments, Rev. Geophys., 47, RG4003, doi:10.1029/2008RG000279.

Weast, R. C. (1987), CRC Handbook of Chemistry and Physics, 68 ed., CRC Press, Boca Raton, Fla.

Weinberger, J. L., and K. M. Brown (2006), Fracture networks and hydrate distribution at Hydrate Ridge, Oregon, Earth Planet. Sci. Lett., 245(1-2), 123-136, doi:10.1016/j.eps1.2006.03.012.

Westbrook, G. K., et al. (1994), Proceedings of the Ocean Drilling Program, Scientific Results, vol. 146, part 1, Ocean Drill. Program, College Station, Tex.

Winters, W. J. (2000a), Data report: Effects of drying methods and temperatures on water content and porosity of sediment from the Blake Ridge, Proc. Ocean Drill. Program Sci. Results, 164, 421-429.

Winters, W. J. (2000b), Stress history and geotechnical properties of sediment from the Cape Fear Diapir, Blake Ridge Diapir, and Blake Ridge, Proc. Ocean Drill. Program Sci. Results, 164, 431-434.

Winters, W. J., W. F. Waite, D. H. Mason, and P. Kumar (2008), Physical properties of repressurized samples recovered during the 2006 National Gas Hydrate Program Expedition offshore India, paper presented at 6th International Conference on Gas Hydrates, Chevron, Vancouver, B. C., Canada, 6-10 July.

Winters, W., M. Walker, R. Hunter, T. Collett, R. Boswell, K. Rose, W. Waite, M. Torres, S. Patil, and A. Dandekar (2011), Physical properties of sediment from the Mount Elbert Gas Hydrate Stratigraphic Test Well, Alaska North Slope, Mar. Pet. Geol., 28, 361-380, doi:10.1016/ j.marpetgeo.2010.01.008.

Wood, W. T., and W.-Y. Jung (2008), Modeling the extent of Earth's marine methane hydrate cryosphere, paper presented at 6 th International Conference on Gas Hydrates, Chevron, Vancouver, B. C., Canada, 6-10 July.

Xia, W., and M. F. Thrope (1988), Percolation properties of random ellipses, Phys. Rev. A, 38(5), 2650-2656, doi:10.1103/PhysRevA.38.2650.

Yun, T. S., F. M. Francisca, J. C. Santamarina, and C. Ruppel (2005), Compressional and shear wave velocities in uncemented sediment containing gas hydrate, Geophys. Res. Lett., 32, L10609, doi:10.1029/2005GL022607.

Yun, T. S., G. A. Narsilio, and J. C. Santamarina (2006), Physical characterization of core samples recovered from Gulf of Mexico, Mar. Pet. Geol., 23, 893-900, doi:10.1016/j.marpetgeo.2006.08.002.

Yun, T. S., J. C. Santamarina, and C. Ruppel (2007), Mechanical properties of sand, silt, and clay containing tetrahydrofuran hydrate, J. Geophys. Res., 112, B04106, doi:10.1029/2006JB004484.

Yun, T. S., D. Fratta, and J. C. Santamarina (2010), Hydrate-bearing sediments from the Krishna-Godavari Basin: Physical characterization, pressure core testing, and scaled production monitoring, Energy Fuels, 24(11), 5972-5983, doi:10.1021/ef100821t

Yun, T. S., J. S. Lee, J. J. Bahk, and J. C. Santamarina (2011), Geotechnical characterization of marine sediments in the Ulleung Basin, East Sea, Eng. Geol., 117(1-2), 151-158.

Zimmerman, R. W., and G. S. Bodvarsson (1995), The effect of rock fragments on the hydraulic properties of soils, Rep. LBNL-37018, 27 pp., Lawrence Berkeley Natl. Lab., Berkeley, Calif.

Zimmerman, R. W., S. Kumar, and G. S. Bodvarsson (1991), Lubrication theory analysis of the permeability of rough-walled fractures, Int. J. Mech. Min. Sci. Geomech. Abstr., 28, 325-331, doi:10.1016/01489062(91)90597-F. 